\title{
Inheritance of Resistance to Verticillium dahliae in Diploid Interspecific Potato Hybrids
}

\author{
Shelley Jansky, Professor, Department of Biology, University of Wisconsin-Stevens Point, 54481; D. I. Rouse, Pro- \\ fessor, Department of Plant Pathology, University of Wisconsin-Madison 53706; and P. J. Kauth, Department of \\ Biology, University of Wisconsin-Stevens Point
}

\begin{abstract}
Jansky, S., Rouse, D. I., and Kauth, P. J. 2004. Inheritance of resistance to Verticillium dahliae in diploid interspecific potato hybrids. Plant Dis. 88:1075-1078.

Verticillium wilt is a serious disease in potato and is caused primarily by the soilborne fungi Verticillium dahliae and V. albo-atrum. Host plant resistance to the disease offers an option for long-term, inexpensive, and environmentally sound control. High levels of resistance to stem colonization have been identified in two diploid hybrids between the cultivated potato and wild Solanum spp. An intercross between the two clones produced a 3:1 ratio of resistant to susceptible clones. A cross between a susceptible clone and one of the resistant clones also produced a 3:1 resistant:susceptible ratio. These data can be explained by a two-gene model, in which dominant alleles of both genes must be present to confer resistance. The two-gene model also explains data from previous research with wild Solanum spp. A simple mode of inheritance should improve the probability of producing resistant offspring when resistant hybrids are used as parents in a breeding program.
\end{abstract}

Additional keywords: complementary gene action

One of the most important problems encountered by potato producers is Verticillium wilt, caused in large part by the fungal pathogens Verticillium dahliae Kleb. and V. albo-atrum Reinke \& Berthold (8). The disease is a limiting factor for production of all commercially significant cultivars (20). The most effective control method for Verticillium wilt is soil fumigation (21), which is expensive. In addition, recent reports of misuse of fumigants have highlighted the potential for negative environmental and human health effects. Restrictions on use of these environmentally damaging chemicals seem likely in the near future. Finally, fumigants may destroy beneficial microflora and fauna in the soil (19). Other Verticillium wilt control methods are marginally effective at best. Practices such as nitrogen and water management have been shown to improve yield in the presence of Verticillium spp., but not sufficiently to consistently achieve economic control $(18,21)$. Biological control has potential, but its effectiveness probably will be variable, due to differential effects

Corresponding author: S. Jansky

E-mail: shjansky@wisc.edu

This work was funded in part by the United States Department of Agriculture-Agricultural Research Service (59-0790-1-061).

Accepted for publication 6 May 2004.

Publication no. D-2004-0727-01R

(C) 2004 The American Phytopathological Society of the environment on those organisms. Crop rotation is ineffective because microsclerotia of the fungus survive in the soil for up to 10 years $(15,17)$.

A promising alternative method of Verticillium wilt control is host plant resistance. In potato, Verticillium wilt resistance is heritable $(1,4,7,10,12)$ and appears to be stable over time (5). However, resistance in commercially significant potato cultivars is moderate at best. Alternatively, high levels of Verticillium wilt resistance have been identified in wild Solanum spp. $(4,6)$. Jansky and Rouse $(13,14)$ have identified two diploid interspecific hybrid clones (C287 and C545) with high levels of Verticillium wilt resistance.

There are few published studies on the inheritance of Verticillium wilt resistance in wild Solanum spp. Concibido et al. (4) suggested that resistance to $V$. dahliae in hybrids between wild Solanum spp. is polygenic because family distributions were continuous. However, distributions were skewed toward resistance; therefore, the authors suggested that dominant resistance genes might be present. Lynch et al. (16) have reported that a single dominant gene in $S$. chacoense is responsible for resistance to $V$. albo-atrum. In tomato, a single dominant gene confers Verticillium wilt resistance (22). This resistance gene has been incorporated into numerous tomato cultivars.

An understanding of the inheritance of resistance is important because breeding strategies will vary depending on whether resistance is based on a limited number of genes or multiple genes. It also is important to know whether resistance is conferred by dominant or recessive alleles. If resistance is simply inherited and dominant, it should easily be transferred to cultivated germ plasm and expressed at both the diploid and tetraploid level.

This study was carried out to determine the genetic basis of Verticillium wilt resistance in potato. Resistance was evaluated in progeny of a cross between two diploid, resistant interspecific hybrids and a testcross between a susceptible Solanum tuberosum dihaploid $(2 \mathrm{x})$ and one of the resistant clones.

\section{MATERIALS AND METHODS}

The two diploid $(2 n=2 \mathrm{x}=24)$, resistant clones in this study are diploid interspecific hybrids with the following pedigrees: C287 (US-W730 $\times[S$. berthaultii $\times$ $S$. tarijense $]) \times(\mathrm{US}-\mathrm{W} 730 \times S$. tarijense $)$ and C545 $(\mathrm{H} 551 \times$ S. chacoense $) \times(\mathrm{US}-$ $\mathrm{W} 730 \times[S$. berthaultii $\times S$. tarijense $])$. US-W730 is a dihaploid $(2 n=2 \mathrm{x}=24)$ derived from the tetraploid breeding clone Wis Ag 231, whereas H551 is a dihaploid of unknown parentage. Reciprocal crosses were made between C287 and C545, but seed were obtained only from the cross using C287 as the male parent. Both resistant clones were crossed as males to the male sterile dihaploid Atl175, which was derived from 'Atlantic.' Seed were obtained from the C287 but not the C545 cross. In April 2000, seed from the C545 × C287 cross were soaked in gibberellic acid $\left(\mathrm{GA}_{3}\right)$ at $1,500 \mathrm{ppm}$ for $24 \mathrm{~h}$ to break dormancy and then sown in a peat-based potting mix in a greenhouse. Six weeks later, they were transplanted to the field at the Hancock (WI) Agricultural Experiment Station and grown using standard cultural practices. The soil is a Plainfield loamy sand (92\% sand, $5 \%$ silt, $3 \%$ clay, $<1 \%$ organic matter). In October, each plant was harvested by hand and maintained as a separate clone. Clones from the Atl175 $\times$ C287 cross were produced in the same manner in 2001.

The two resistant parents and their progeny were evaluated in a Verticillium wilt screening field at Hancock in 2001, 2002, and 2003. This field has been planted continuously to potatoes for over 30 years and contains approximately $50 \mathrm{CFU}$ of $\mathrm{V}$. dahliae per gram of soil. Uniform infestation of the soil in this field has been confirmed 
with repeated visual, soil, and potato stem data. Tubers were planted in four replications of four-hill plots on 4 May 2001, 30 April 2002, and 1 May 2003. Although 95 clones were planted in 2001, several exhibited poor tuberization or storage quality; therefore, 55 and 56 clones were available for evaluation in 2002 and 2003, respectively. Standard cultural practices were followed and plants were allowed to senesce naturally.

The most common method of scoring for Verticillium wilt resistance is to visually evaluate symptom expression in plants grown in infested soil. However, the plants segregate for a number of factors that confound wilt scores. Maturity and accumulation of mineral nutrients are among the factors that can confound scores. In the test plot (soil pH 6.8), the two resistant clones hyperaccumulate certain divalent cations (iron, aluminum, and manganese), resulting in chlorosis due to mineral toxicity. This trait segregates in their offspring and is difficult to separate from chlorosis due to Verticillium wilt. The relationship between mineral uptake and Verticillium wilt resistance currently is under investigation. In order to avoid the confounding effect of mineral toxicity chlorosis on symptom expression, the technique of Davis et al. (9) is used to assess disease. This method measures the ability of the fungus to colonize stem tissue and form microsclerotia in the stem cortex. A variation of this technique was developed by Hoyos et al. (11), in which stem colonization is measured in sap collected from living stems. This technique mainly measures populations of conidia.

In 2001 and 2002, beginning in midAugust, the field was examined weekly and stems from dead plants were collected and air dried. Apical and basal portions of all stems from each plot were bulked and ground in a Wiley mill with a 40-mesh screen, and $50 \mathrm{mg}$ was plated on NPX medium (2). After a 2-week incubation period in the dark at room temperature, the stem debris was washed off each plate and the number of $V$. dahliae colonies per plate was recorded as a measure of stem colonization. Processing of stems in 2003 was the same as in the previous 2 years, except that only basal stem sections from four hills were collected on one date, $19 \mathrm{Au}$ gust.

On 1 May, 2003, clones from the Atl175 $\times$ C287 test cross were planted along with their parents on the Verticillium wilt screening field at Hancock. They were planted in four replications of four hill plots. On 14 July, basal stem segments were collected from two plants in each plot. The day after collection, stems were surface disinfested with $1 \% \mathrm{NaOCl}$ and rinsed in sterile distilled water, after which sap was pressed out. A $100-\mu$ l aliquot was plated on NPX medium and the plate was incubated in the dark at room temperature for 2 weeks. The number of $V$. dahliae colonies per plate then was recorded as a measure of stem colonization. On $18 \mathrm{Au}-$ gust, basal stem segments were collected from the remaining two plants per plot. They were processed as described above to measure colonization in dried stems.

An analysis of variance was performed on transformed $(\log n+1)$ colony count data using the General Linear Model in SAS. Means were separated using the least significant difference (LSD) test at $P=$ 0.05 . Pearson's correlation coefficient was calculated using SAS, and $\chi^{2}$ values were calculated using the following formula (where res. $=$ resistant, sus. $=$ susceptible, exp. $=$ expected $): \chi^{2}=[($ no. res. clones exp. no. res. clones $)^{2} /$ exp. no. res. clones] $+[$ (no. sus. clones - exp. no. sus. clones) ${ }^{2} /$ exp. no. sus. clones].

\section{RESULTS}

Although pollen from both resistant clones appears to be viable because it is highly stainable with $0.5 \%$ acetocarmine (data not shown), C545 did not produce any offspring as a male parent. It is interesting that it has produced offspring when used as a male parent in crosses to tetraploids.

In each trial, the resistant parents had low stem colonization scores, while the susceptible parent had higher scores (Table 1). C545 had higher levels of stem colonization than $\mathrm{C} 287$, but the numbers were never significantly different from each other $(P>0.05)$. Progeny means were low, although some clones had high stem colonization scores. Therefore, a large proportion of clones in each population had low levels of stem colonization.

For the $\chi^{2}$ analysis of the C545 × C287 (resistant $\times$ resistant) family, clones that were significantly more susceptible than both parents, based on the LSD test, were considered to be susceptible. The family was skewed toward resistance (Fig. 1) and a 3:1 resistant:susceptible ratio was observed in all analyses (Table 2). The Pearson correlation coefficient between the apical and basal dried stem data are highly significant $(P<0.0001)$ in each year and in the combined analysis. The value was 0.45 in 2001 and 0.52 in 2002. Highly significant clone, year, and clone-year effects $(P$ $<0.001$ ) were observed for the apical stem

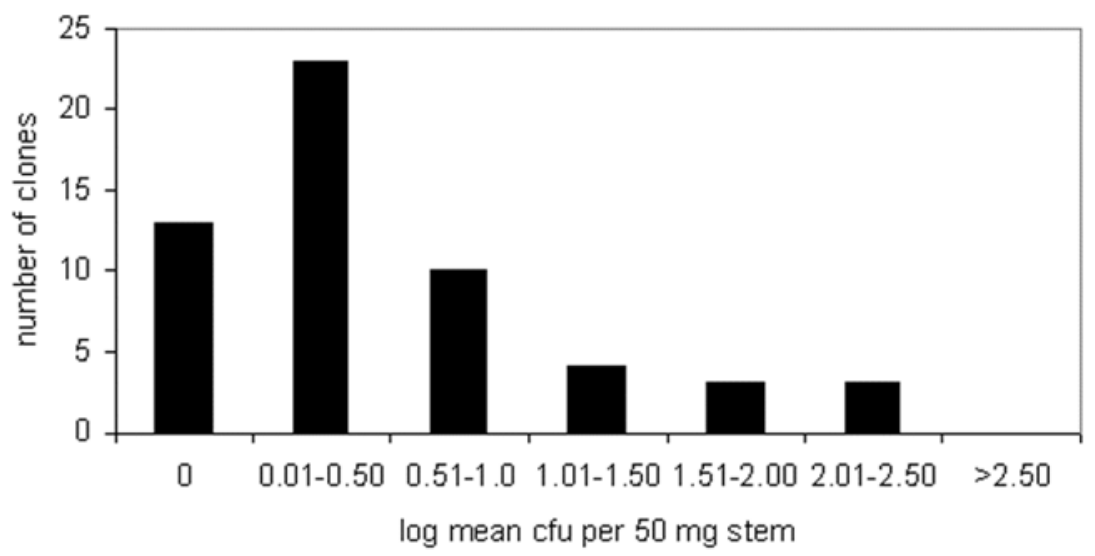

Fig. 1. Distribution of clones in the C545 $\times$ C287 family (2003) based on basal dry sap scores. Mean scores for both C545 and C287 were 0.00 .

Table 1. Mean Verticillium dahliae stem colonization scores (CFU/50 mg for dry stem tissue; CFU/100 $\mu$ of sap for fresh stem tissue) for C545, C287, Atl 175 , and their progeny in 2001,2002 , and 2003

\begin{tabular}{|c|c|c|c|c|c|c|c|}
\hline \multirow[b]{2}{*}{ Year } & \multirow[b]{2}{*}{ Cross } & \multirow[b]{2}{*}{ Type of cross ${ }^{a}$} & \multirow[b]{2}{*}{ Stem source } & \multicolumn{3}{|c|}{ Parents } & \multirow[b]{2}{*}{ Progeny (range) ${ }^{\mathbf{b}}$} \\
\hline & & & & $\mathrm{C} 287$ & C545 & Atl 175 & \\
\hline \multirow[t]{2}{*}{2001} & $\mathrm{C} 545 \times \mathrm{C} 287$ & $\mathrm{R} \times \mathrm{R}$ & Apical dry & 0.1 & 1.7 & $\ldots$ & $1.4 \pm 3.4(0-105)$ \\
\hline & $\mathrm{C} 545 \times \mathrm{C} 287$ & $\mathrm{R} \times \mathrm{R}$ & Basal dry & 0.0 & 2.3 & $\ldots$ & $2.1 \pm 4.1(0-117)$ \\
\hline \multirow[t]{2}{*}{2002} & $\mathrm{C} 545 \times \mathrm{C} 287$ & $\mathrm{R} \times \mathrm{R}$ & Apical dry & 0.4 & 5.1 & $\ldots$ & $4.8 \pm 5.9(0-284)$ \\
\hline & $\mathrm{C} 545 \times \mathrm{C} 287$ & $\mathrm{R} \times \mathrm{R}$ & Basal dry & 0.0 & 6.8 & $\ldots$ & $2.8 \pm 3.3(0-19)$ \\
\hline \multirow[t]{3}{*}{2003} & $\mathrm{C} 545 \times \mathrm{C} 287$ & $\mathrm{R} \times \mathrm{R}$ & Basal dry & 0.0 & 0.0 & $\ldots$ & $2.8 \pm 6.3(0-212)$ \\
\hline & Atl175 × C287 & $\mathrm{S} \times \mathrm{R}$ & Basal dry & 1.8 & $\ldots$ & 23.7 & $6.5 \pm 8.2(0-330)$ \\
\hline & At1 $175 \times$ C 287 & $\mathrm{~S} \times \mathrm{R}$ & Basal sap & 0.0 & $\ldots$ & 5.0 & $0.6 \pm 2.3(0-3)$ \\
\hline
\end{tabular}

\footnotetext{
a $\mathrm{R}=$ resistant and $\mathrm{S}=$ susceptible.
}

b Standard deviation of error. 
data. In contrast, for the basal data, highly significant clone effects $(P<0.0001)$ were observed, but year effects were not significant $(P=0.85)$ and the clone-year effect was significant at $P=0.03$. In addition, the standard deviation for the apical scores (4.5) was greater than that for the basal scores (3.8).

The Pearson correlation coefficient between the dried stem and sap data in the At1175 $\times \mathrm{C} 287$ cross was $0.21(P=$ 0.0038). This is similar to that reported by Jansky and Rouse (14). Therefore, both sap and dried stem data sets were used to evaluate resistance.

For the $\chi^{2}$ analysis of the At1 $175 \times \mathrm{C} 287$ (susceptible $\times$ resistant) family, clones that were at least as susceptible as Atl175, based on the LSD test, were considered to be susceptible. The data did not fit a 1:1 resistant:susceptible ratio, which would be expected if a single dominant gene conferred resistance $\left(v_{\mathrm{w}} v_{\mathrm{w}} \times V_{\mathrm{w}} v_{\mathrm{w}}\right)$. However, as with the C545 $\times$ C287 family, the population was skewed toward resistance (Fig. 2) and the data closely fit a 3:1 resistant:susceptible ratio (Table 2).

\section{DISCUSSION}

Data from the C545 × C287 cross support the hypothesis that a single gene for resistance is segregating in this population and resistance is due to a dominant allele. We propose that both resistant parents are heterozygous for a dominant resistance gene derived from one or more wild species $\left(V_{\mathrm{w}}\right)$, producing an offspring population with $75 \%$ resistant plants. It is not yet known whether this is the same gene that confers resistance to $V$. albo-atrum in

Table 2. Numbers of Verticillium dahliae resistant and susceptible plants in C287 × C545 and Atl175 $\times$ C287 families and $\chi^{2}$ values based on a 3:1 resistant:susceptible ratio ${ }^{\mathrm{a}}$

\begin{tabular}{llclrrr}
\hline Year & Cross & Type of cross & Stem source & $\mathbf{R}^{\mathbf{b}}$ & $\mathbf{S}^{\mathbf{b}}$ & $\chi^{\mathbf{2 c}}$ \\
\hline 2001 & C545 $\times$ C287 & $\mathrm{R} \times \mathrm{R}$ & Apical dry & 78 & 17 & 2.56 \\
& $\mathrm{C} 545 \times \mathrm{C} 287$ & $\mathrm{R} \times \mathrm{R}$ & Basal dry & 74 & 21 & 0.42 \\
2002 & $\mathrm{C} 545 \times \mathrm{C} 287$ & $\mathrm{R} \times \mathrm{R}$ & Apical dry & 46 & 9 & 2.19 \\
& $\mathrm{C} 545 \times \mathrm{C} 287$ & $\mathrm{R} \times \mathrm{R}$ & Basal dry & 42 & 13 & 0.05 \\
2003 & C545 $\times$ C287 & $\mathrm{R} \times \mathrm{R}$ & Basal dry & 46 & 10 & 1.52 \\
& At1175 $\times$ C287 & $\mathrm{S} \times \mathrm{R}$ & Basal dry & 35 & 11 & 0.03 \\
& At1175 $\times$ C287 & $\mathrm{S} \times \mathrm{R}$ & Basal sap & 33 & 12 & 0.07 \\
\hline
\end{tabular}

${ }^{\text {a }}$ Proposed parental genotypes are C287 and C545 $=V_{\mathrm{w}} v_{\mathrm{w}} V_{\mathrm{t}} V_{\mathrm{t}}$, and At1175 $=V_{\mathrm{w}} v_{\mathrm{w}} v_{\mathrm{t}} v_{\mathrm{t}}$.

${ }^{\mathrm{b}} \mathrm{R}=$ resistant, $\mathrm{S}=$ susceptible. For the $\mathrm{C} 545 \times \mathrm{C} 287$ family, susceptible = significantly more susceptible than both parents; for the At1175 $\times \mathrm{C} 287$ family, susceptible $=$ at least as susceptible as Atl175.

${ }^{c}$ Critical $\chi^{2}$ value $=3.841$ at $P=0.05$.

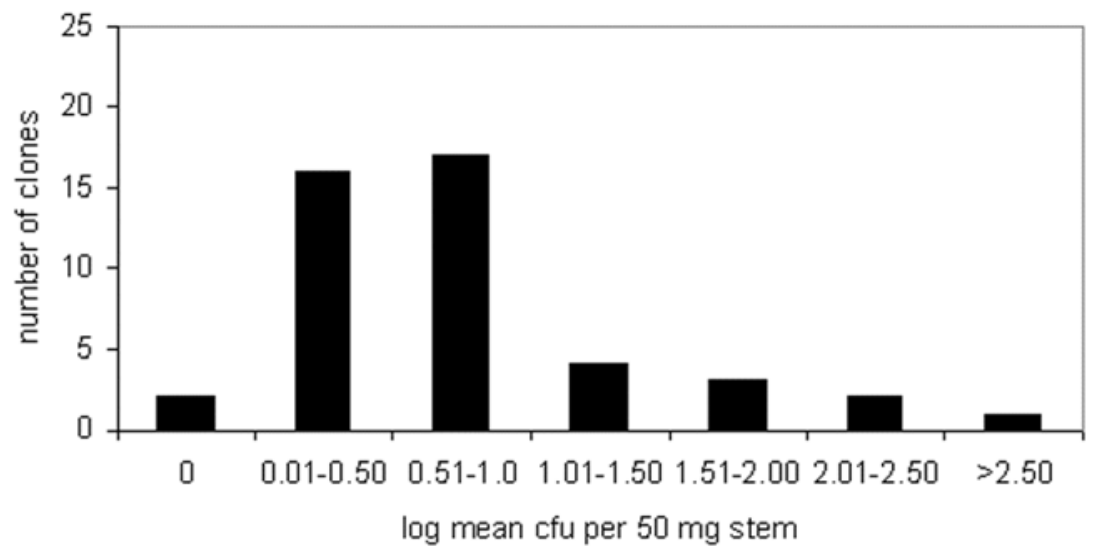

Fig. 2. Distribution of clones in the At1175 × C287 family (2003) based on dry stem scores. Mean scores for Atl175 and C287 were 1.39 and 0.45 , respectively.
S. chacoense as reported by Lynch et al. (16).

Although both apical and basal stem techniques measure stem colonization and microsclerotia formation in senescing tissue, the fungus would not be expected to reach apical stem tissue as often as basal tissue. More variability would be expected, therefore, in apical than in basal scores. This was, in fact, observed especially in the analysis combined across years.

The $\chi^{2}$ values were higher for apical than basal scores, due to an excess of apparently resistant clones in which the basal infection did not extend into the stem apices. These clones were considered resistant based on low apical stem scores, but their basal tissue contained propagules, causing them to be classified as susceptible in the basal stem analysis.

If resistance is due to a single dominant gene, then the Atl175 (susceptible) $\times \mathrm{C} 287$ cross should produce a family with $50 \%$ resistant clones. However, a 3:1 ratio of resistant to susceptible clones was observed. This ratio could be explained by a two-gene model in which there is complementary gene action, so that dominant alleles of both genes are necessary for resistance.

The proposed genotypes of the resistant clones (C287 and C545) are $V_{\mathrm{w}} v_{\mathrm{w}} V_{\mathrm{t}} V_{\mathrm{t}}$, while that of the susceptible clone (Atl175) is $V_{\mathrm{w}} v_{\mathrm{w}} v_{\mathrm{t}} v_{\mathrm{t}}$. In this study, $V_{\mathrm{t}}$ was not detected until the susceptible, predominantly S. tuberosum parent (Atl175) was introduced. Perhaps $S$. tuberosum lacks the dominant form of the $V_{\mathrm{t}}$ gene, so that all cultivated potato lines are susceptible. The two resistant clones (C287 and C545) may have received the $V_{\mathrm{t}}$ alleles from their wild species parents, because wild species were on both sides of their pedigrees.

Concibido (4) intercrossed wild Solanum spp. and evaluated the offspring by inoculating with $V$. dahliae and scoring for propagules in stem sap. The authors suggested that resistance is polygenic, because a continuous distribution of the data was observed for each family. However, a continuous distribution could be observed even with simple inheritance, due to the nature of the scoring method. Colony counts do not fall into discrete categories. However, if the variation among susceptible clones is ignored, as was done in the

Table 3. Concibido (1990) data in support of a complementary gene action hypothesis for resistance to Verticillium dahliae

\begin{tabular}{|c|c|c|c|c|c|c|}
\hline Cross $^{\mathrm{a}}$ & Type of cross ${ }^{b}$ & Proposed genotypes & $\mathbf{R}$ & $\mathbf{S}$ & Ratio (R:S) & $\chi^{2 \mathrm{c}}$ \\
\hline $\operatorname{can} 1 \times \operatorname{chc} 2$ & $\mathrm{~S} \times \mathrm{R}$ & $v_{\mathrm{w}} v_{\mathrm{w}} v_{\mathrm{t}} v_{\mathrm{t}} \times V_{\mathrm{w}} v_{\mathrm{w}} V_{\mathrm{t}} v_{\mathrm{t}}$ & 24 & 76 & $1: 3$ & 0.05 \\
\hline chc $1 \times \operatorname{grl} 1$ & $\mathrm{R} \times \mathrm{S}$ & $V_{\mathrm{w}} v_{\mathrm{w}} V_{\mathrm{t}} v_{\mathrm{t}} \times v_{\mathrm{w}} v_{\mathrm{w}} v_{\mathrm{t}} v_{\mathrm{t}}$ & 26 & 74 & $1: 3$ & 0.05 \\
\hline $\operatorname{grl} 1 \times$ chc 1 & $\mathrm{~S} \times \mathrm{R}$ & $v_{\mathrm{w}} v_{\mathrm{w}} v_{\mathrm{t}} v_{\mathrm{t}} \times V_{\mathrm{w}} v_{\mathrm{w}} V_{\mathrm{t}} v_{\mathrm{t}}$ & 38 & 62 & $1: 3$ & 9.01 \\
\hline $\operatorname{grl} 1 \times \operatorname{chc} 1^{\mathrm{d}}$ & $\mathrm{S} \times \mathrm{R}$ & $v_{\mathrm{w}} v_{\mathrm{w}} v_{\mathrm{t}} v_{\mathrm{t}} \times V_{\mathrm{w}} v_{\mathrm{w}} V_{\mathrm{t}} v_{\mathrm{t}}$ & 21 & 54 & $1: 3$ & 0.36 \\
\hline phu $1 \times$ rap 2 & $\mathrm{MS} \times \mathrm{S}$ & $v_{\mathrm{w}} v_{\mathrm{w}} v_{\mathrm{t}} v_{\mathrm{t}} \times v_{\mathrm{w}} v_{\mathrm{w}} V_{\mathrm{t}} v_{\mathrm{t}}$ & 6 & 91 & $0: 1$ & $\ldots$ \\
\hline phu $2 \times$ can 1 & $\mathrm{MS} / \mathrm{R} \times \mathrm{S}$ & $V_{\mathrm{w}} v_{\mathrm{w}} V_{\mathrm{t}} v_{\mathrm{t}} \times v_{\mathrm{w}} v_{\mathrm{w}} v_{\mathrm{t}} v_{\mathrm{t}}$ & 18 & 82 & $1: 3$ & 2.16 \\
\hline rap $1 \times$ can 1 & $\mathrm{~S} \times \mathrm{S}$ & $\ldots \times v_{\mathrm{w}} v_{\mathrm{w}} v_{\mathrm{t}} v_{\mathrm{t}}$ & 3 & 97 & $0: 1$ & $\ldots$ \\
\hline
\end{tabular}

${ }^{a}$ Species: can $=$ Solanum canasense, $\mathrm{chc}=S$. chacoense, grl $=$ S. gourlayi, $\mathrm{phu}=$ S. tuberosum $\mathrm{Gp}$. Phureja, and rap $=$ S. raphanifolium.

${ }^{\mathrm{b}} \mathrm{R}=$ resistant, $\mathrm{S}=$ susceptible, and MS = moderately susceptible (0 to 499, 1,000+, and 500-999 CFU/100 $\mu$ l of sap, respectively).

${ }^{c}$ Critical $\chi^{2}$ value $=3.841$ at $P=0.05$.

${ }^{\mathrm{d}}$ Data from reps 2-4. 
current study and that by Lynch et al. (16), then the data can be put into the discrete classes of resistant and susceptible clones. When this is done with the data in Concibido's thesis (3), a model based on complementary gene action is supported (Table 3). In this study, clones were considered resistant, moderately susceptible, or susceptible if they contained an average of 0 to 499,500 to 999 , or at least 1,000 CFU/100 $\mu \mathrm{l}$ of sap, respectively. In one family $(S$. gourlayi $1 \times S$. chacoense 1$)$, there was an excess of resistant clones in the first replication (17 resistant, 8 susceptible). Perhaps the inoculation procedure was not effective in that replication, resulting in a large number of escapes. When data from that aberrant replication are excluded, then the remaining data fit the expected ratio (21 resistant, 54 susceptible; $\left.\chi^{2}[1: 3]=0.36\right)$. In the Group Phureja $\times S$. canasense family, the Phureja parent was classified as moderately susceptible, but the data indicate that it might better be classified as resistant. Data from this study support the conclusion of Lynch et al. (16), that resistance to Verticillium wilt is simply inherited and dominant. Lynch et al. (16) observed only a single gene for resistance; therefore, their population apparently was not segregating for a second gene, as were the populations in this and Concibido's (3) studies. It should not be difficult to transfer this resistance to the tetraploid level via unilateral sexual polyploidization ( $4 \mathrm{x} \times 2 \mathrm{x}$ and $2 \mathrm{x} \times 4 \mathrm{x}$ crosses $)$. In fact, preliminary data indicate that resistance effectively is transferred when C287 and C545 are crossed to the susceptible $S$. tuberosum cv. Atlantic and two tetraploid breeding clones.

\section{LITERATURE CITED}

1. Akeley, R. V., Stevenson, F. J., Folson, D., and Bonde, R. 1956. Breeding varieties of potato resistant to Verticillium wilt in Maine. Am. Potato J. 33:15-21.

2. Butterfield, E. J., and DeVay, J. E. 1977. Reassessment of soil assays for Verticillium dahliae. Phytopathology 67:1073-1078.

3. Concibido, V. C. 1990. Inheritance study on Verticillium wilt resistance in diploid wild potatoes. M.S. thesis. North Dakota State University, Fargo.

4. Concibido, V. C., Secor, G. A., and Jansky, S. H.. 1994. Evaluation of resistance to Verticillium wilt resistance in diploid, wild potato interspecific hybrids. Euphytica 76:145-152.

5. Corsini, D. L., Davis, J. R., and Pavek, J. J. 1985. Stability of resistance of potato to strains of $V$. dahliae from different vegetative compatibility groups. Plant Dis. 69:980-982.

6. Corsini, D. L., Pavek, J. J., and Davis, J. R. 1988. Verticillium wilt resistance in noncultivated tuber-bearing Solanum species. Plant Dis. 72:148-151.

7. Corsini, D. L., Pavek, J. J., and Davis, J. R. 1990. Verticillium wilt resistant potato germplasm: A66107-51 and A68113-4. Am. Potato J. 67:517-525.

8. Davis, J. R. 1985. Approaches to control of potato early dying caused by $V$. dahliae. Am. Potato J. 62:177-185.

9. Davis, J. R., Pavek, J. J., and Corsini, D. L. 1983. A sensitive method for quantifying Verticillium dahliae colonization in plant tissue and evaluating resistance among potato genotypes. Phytopathology 73:1009-1014.

10. Hoyos, G. P., Lauer, F. I., and Anderson, N. A. 1993. Early detection of Verticillium wilt resistance in a potato breeding program. Am. Potato J. 70:535-541.

11. Hoyos, G. P., Zambino, P. J., and Anderson, N.
A. 1991. An assay to quantify vascular colonization of potato by $V$. dahliae. Am. Potato J. 68:727-742.

12. Hunter, D. E., Darling, H. M., Stevenson, F. J., and Cunningham, C. E. 1968. Inheritance of resistance to Verticillium in Wisconsin. Am Potato J. 45:72-78.

13. Jansky, S. H., and Rouse, D. I. 2000. Verticillium wilt resistance in potato interspecific hybrids: Identification of highly resistant clones and considerations for resistance breeding. Potato Res. 43:239-251.

14. Jansky, S. H., and Rouse, D. I. 2003. Multiple disease resistance in potato interspecific hybrids. Plant Dis. 87:266-272.

15. Lacy, M. L., and Horner, C. E. 1966. Behaviour of $V$. dahliae in the rhizosphere and on roots of plants susceptible, resistant, and immune to wilt. Phytopathology 56:427-430.

16. Lynch, D. R., Kawchuk, L. M., Hachey, J., Bains, P. S., and Howard, R. J. 1997. Identification of a gene conferring high levels of resistance to Verticillium wilt in Solanum chacoense. Plant Dis. 81:1011-1014.

17. Martinson, C. A., and Horner, C. E. 1962 Importance of nonhosts in maintaining the inoculum potential of Verticillium. (Abstr.) Phytopathology 52:742.

18. O'Sullivan, J., and Reyes, A. A. 1980. Effects of soil fumigation, rotation, and nitrogen on yield, petiole $\mathrm{NO}_{3}-\mathrm{N}$, and Verticillium wilt of potatoes. J. Am. Soc. Hortic. Sci. 105:809-812.

19. Pegg, G. F. 1974. Verticillium diseases. Rev. Plant Pathol. 53:157-182.

20. Powelson, M. L., and Rowe, R. C. 1993. Biology and management of early dying of potatoes. Annu. Rev. Phytopathol. 31:111-126.

21. Rowe, R. C., Davis, J. R., Powelson, M. L., and Rouse, D. I. 1987. Potato early dying: causal agents and management strategies. Plant Dis. 71:482-489.

22. Schaible, L., Cannon, O. S., and Waddoups, V. 1951. Inheritance of resistance to Verticillium wilt in a tomato cross. Phytopathology 41:986990. 